\title{
Research Paper: The Effect of Elementary School Teachers' Knowledge of Learning Disabilities on Referring Afflicted Students to Speech Therapy
}

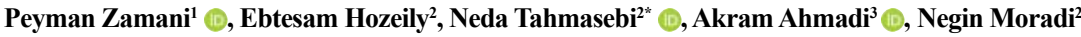 \\ 1. Hearing Research Center, Ahvaz Jundishapur University of Medical Sciences, Ahvaz, Iran. \\ 2. Musculoskeletal Rehabilitation Research Center, Ahvaz Jundishapur University of Medical Sciences, Ahvaz, Iran. \\ 3. Department of Speech Therapy, School of Rehabilitation, Babol University of Medical Sciences, Babol, IR Iran.
}

\begin{tabular}{|c|c|}
\hline $\begin{array}{l}\text { Use your device to scan } \\
\text { and read the article online }\end{array}$ & Citration Zamani P, Hozeily E, Tahmasebi N, Ahmadi A, Moradi N. The Effect of Elementary School Teachers' Knowledge \\
\hline 口iptra & $\begin{array}{l}\text { of Learning Disabilities on Referring Afflicted Students to Speech Therapy. Iranian Rehabilitation Journal. 2018; 16(4):371-378. } \\
\mathrm{http} / / / \mathrm{dx} \text {.doi.org/10.32598/irj.16.4.371 }\end{array}$ \\
\hline mistis & doil http://dx.doi.org/10.32598/irj.16.4.371 \\
\hline
\end{tabular}

Article info:

Received: 01 May 2018

Accepted: 13 Aug 2018

Available Online: 01 Dec 2018

\section{Keywords:}

Learning disabilities, Teachers' awareness, Speech therapy

\section{ABSTRACT}

Objectives: Learning disabilities can cause serious communication and socio-emotional disorders in students. Teachers, as specialists who are in direct contact with students on a daily basis, have an important role in identifying and referring students suspected of these disabilities. Therefore, this study investigated the role of primary school teachers' awareness and attitude about the signs and symptoms of learning disabilities on the referral of students of Ahvaz City, Iran to speech therapy centers.

Methods: This case-control study was conducted on 165 elementary school teachers in Ahvaz in 2016-2017. The teacher's awareness questionnaire was used to determine the teachers' awareness level. A logistic regression test was used to explore the role of teachers' attributes on the referral of students to speech therapies.

Results: The mean total score of teachers' awareness about students' learning disabilities was significantly different in the case and control groups $(\mathrm{P}<0.05)$. Teachers' awareness scores had a direct and significant relationship with working experience $(\mathrm{P}<0.05)$ and participation in educational workshops $(\mathrm{P}<0.05)$. However, there was no significant relationship between the teachers' awareness score with age and gender $(\mathrm{P}>0.05)$.

Discussion: Teaching experience, educational level, history of participation in educational workshops and the teachers' awareness of learning disabilities are critical factors in referring students to speech therapy centers. It is recommended that teachers participate in workshops at regular intervals to update their knowledge on this topic.

\section{* Corresponding Author:}

Neda Tahmasebi, MSc.

Address: Musculoskeletal Rehabilitation Research Center, Ahvaz Jundishapur University of Medical Sciences, Ahvaz, Iran

Tel: +98 (913) 3008869

E-mail: nedatahmasebist@gmail.com 


\section{Highlights}

- Teachers' experience, their level of education, participation in workshops, and awareness of learning disabilities can directly affect their referral of students to speech therapy centers.

- The age and gender of teachers did not affect the rate of referral of students with learning disabilities to speech therapy centers.

\section{Plain Language Summary}

Learning disability of educational skills can cause communicational, emotional and social disorders. Teachers play a key role in diagnosing this problem in their students and referring them to special therapy centers. In this study, we considered those variables related to the teachers' awareness on learning disability. Teachers' work experience, their educational level, participation in educational workshops and awareness level of learning disability had main effect on referring students to speech therapy clinics.

\section{Introduction}

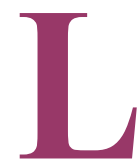

earning disabilities are neurodegenerative disorders with a prevalence rate between $3 \%$ and $12 \%$ in elementary school students [1-4]. This rate was $11.4 \%$ among the third, fourth and fifth grade primary school students in Iran [5]. This rate was similar to that found in America [6]. Genetic factors and prenatal and postnatal conditions may cause learning disabilities [7].

The term "learning disability" was introduced by Samuel Kirk in 1962 [8]. According to the fifth edition of Diagnostic and Statistical Manual of Mental Disorders (DSM-V-TR, 2013), learning disabilities refer to the conditions when academic skills are greatly below the average range of expected scores based on the chronological age (e.g. at least 1.5 SD below the population mean score for age). The difference between intelligence and academic achievement scores in standardized reading, mathematical tests, and written expressions is basically lower than the chronological age, intellectual, and educational level. Learning disabilities significantly affect the academic achievement and daily living activities requiring reading, math or writing skills [9].

Lingeswaran (2013) introduced factors such as a history of language impairment, inability to carry out and maintain activities, weak purposefulness and novelty and the lack of socio-emotional maturity as predictors of learning disabilities [7]. Students with learning disabilities are usually not identified before the third and fourth grades. Consequently, they may miss learning and education opportunities due to secondary problems such as lack of concentration, hyperactivity, communication disorders and depression caused by learning disorders [5].

Most of the students with severe learning disabilities attend exceptional schools due to a misdiagnosis of intellectual disabilities. Those who attend public schools face many challenges in educational progress, which, unfortunately, is the result of $40 \%$ academic failure of these children $[3,5]$. The later the disabilities are identified, the harder the rehabilitation will be. However, the identification and treatment of such children will lead to their $70 \%$ recovery [3, 4]. For this reason, since 1994, the training of students with special needs has become an international concern. Also, countries around the world have committed themselves to provide equal education services for students with special needs as their normal peers [5].

One of the most important strategies for an early age identification of these abnormalities is referring them (by primary school teachers) to rehabilitation practitioners including speech therapists, for accurate and comprehensive assessment and the final diagnosis of childhood learning disorder. This requires that teachers be aware of the signs and symptoms of the disorder and even carry out initial screening of the students [10]. Otherwise, the evaluation and diagnosis may be delayed or lead to undesirable outcomes. Therefore, the awareness and attitudes of primary school teachers about learning disorders are very important [11].

Some studies have reported that the teachers' awareness of learning disabilities is low that results in many challenges in academic achievement of students [12-14]. Kataoka et al. (2004) studied the perception of teachers 
and principals about learning disabilities in Japan. In total, 128 principals and 123 teachers participated in that study. They reported that both principals and teachers need to obtain more knowledge about learning disabilities [12]. Khatib and Jamal investigated the knowledge of teachers in Jordan. They studied 405 elementary school teachers in 3 districts. All of the teachers completed a researcher-made test that included 40 items. They demonstrated that teachers had moderate knowledge about learning disabilities [15].

Abdi et al. reported that teachers' awareness about identification, categorization and the total awareness of learning disabilities was significantly higher in female teachers than male teachers. However, there was no significant differences on the knowledge of rehabilitation between male and female teachers. They concluded that teachers with higher academic education had more awareness about learning disabilities [13]. Arjmandi and Kakabarei reported no significant differences between female and male teachers on the knowledge about learning disabilities. They also reported that academic education had no effect on the knowledge about learning disabilities [2]. Moothedath and Narasimha Vranda (2015) also conducted a study on the knowledge of primary school teachers in India. In total, 200 teachers from 16 schools completed a questionnaire about teachers' knowledge of learning disabilities. They emphasized that teachers should increase their identification knowledge of students with learning disabilities [14].

In many countries, workshops and in-service programs are held for teachers in order to educate children with special needs including learning disabilities in public schools. Such programs help with identifying and diagnosing these disorders in a timely manner [11]. There is still a lack of time management for referring many students with learning disabilities in Iran. It can be because of the low awareness of teachers about these conditions. Therefore, the present study investigated the role of awareness and attitude of primary school teachers as well as other demographic characteristics on the referal time of students with learning disabilities to speech therapists.

\section{Methods}

The participants of the present study were the elementary school teachers in Ahwaz City, Iran. The sample size required for the current study was determined using the sample size determination by $G^{*}$ Power $(\alpha=0.05, \beta=0.95$, $\mathrm{d}=0.71)$. Finally, 165 teachers participated in this casecontrol study and completed the questionnaire of knowledge and attitudes of teachers of children with learning disabilities. Initially, 59 students who were referred to speech therapy clinics with the diagnosis of learning disabilities by school teachers were selected by convenience sampling method. Gender, age, and educational background were identified. Then, the teachers who identified these students and referred them to speech therapy services were identified. A total of 45 elementary public school teachers were identified and enrolled into the case group. A demographic data questionnaire was completed by them.

Characteristics such as teaching experience, degree, gender, and history of participation in workshops constructed the main aspects of this questionnaire. Also, 120 primary school teachers of public schools were randomly selected as the control group who completed the demographic data questionnaire, as well. There were also teachers in the control group who had a history of students' referral to the speech therapy centers, as well as teachers without such history. After collecting the demographic data, all teachers in the two groups completed the questionnaire for determining the knowledge and awareness of elementary school teachers of students with learning disabilities.

Psychometric properties of the questionnaire were investigated by Abdi et al. in Iran (2010). This questionnaire consists of 3 subscales, including teachers' knowledge of the a. learning disabilities symptoms; b. symptoms categorization; and c. existing therapeutic approaches, to improve learning disabilities in elementary school students. This instrument consists of 34 items. The correct and incorrect answers to each question are scored 1 and 0 respectively. The total score indicates the level of knowledge and awareness in elementary school teachers of student learning disabilities. Thus, a score of 0-10 reflects low awareness, 11-20 moderate awareness, 21-30 desirable awareness, and over 30 very good awareness [13]

All of the teachers provided a consent form for participation in the current study. We explained the purposes of our study to them. SPSS was used for statistical analysis. Considering the normal distribution of data, Independent t-test was used for between-group comparisons of continuous quantitative variables. Spearman's correlation coefficient was used to determine the correlation between teachers' characteristics and their awareness level and attitude. Binary logistic regression was used to determine the role of teacher's characteristics on the referral or non-referral of the students to speech therapies. The teachers' gender, level of education, awareness level and attitude scores, and their attendance to workshops 
were separately entered into the logistic regression equation. The significance level was set at $\mathrm{P}<0.05$.

\section{Results}

The baseline characteristics of both groups of teachers are presented in Table 1 . Table 2 presents the total mean and standard deviation scores of awareness and attitude of teachers of students with learning disabilities in the case and control groups. There was a significant difference between the scores of groups in the questionnaire $(\mathrm{P}<0.001)$.

According to Table 3, in both case and control groups, the awareness and attitude scores of teachers had a direct and significant relationship with the working experience $(\mathrm{P}<0.001)$ and the history of participation in workshops $(\mathrm{P}<0.001)$. In addition, in the control group, the awareness and attitude scores of teachers had a direct and significant relationship with their level of education $(\mathrm{P}=0.04)$. However, in the case and control groups, there was no significant correlation between the awareness score of teachers, and age. Furthermore, in the case group, there was no significant correlation between teachers' awareness scores and educational level $(\mathrm{P}>0.05)$.
After performing initial analysis, the logistic regression test was used to determine the weight and role of each characteristic of the teachers on the referral or non-referral of students (Table 4). As presented, teaching experience, teacher's educational level, awareness test scores and a history of workshop participation significantly affected the referral of students with suspected learning disabilities to speech therapies $(\mathrm{P}<0.003)$. However, the age and gender of teachers did not affect the rate of referral of students with learning disabilities to speech therapies $(\mathrm{P}>0.05)$.

\section{Discussion}

The current study determined the effective factors on the timely referral of students suspected of learning disabilities to speech therapy centers by elementary school teachers. The obtained results indicated that the level of awareness and attitude was different between the case and control groups regarding learning disabilities in the three areas of identification, classification, and rehabilitation (Table 2). Therefore, the Iranian teachers had a relatively low awareness of students' learning disabilities.

This finding is in line with the studies by Kataoka et al. (2004), Moothedath and Narasimha Vranda (2015),

Table 1. Description of subjects' demographic characteristics

\begin{tabular}{|c|c|c|c|c|}
\hline \multirow{2}{*}{ Demographic Particulars } & \multirow{2}{*}{ Components } & \multicolumn{2}{|c|}{ Groups } & \multirow{2}{*}{ Test for Differences } \\
\hline & & Case $(n=45)$ & Control $(n=120)$ & \\
\hline Age, $y$ & Mean \pm SD & $43.5 \pm 4.4$ & $44.1 \pm 3.9$ & $t=0.55, P=0.67$ \\
\hline \multirow[b]{2}{*}{ Gender } & Female & $30(66.7 \%)$ & $78(65.0 \%)$ & \multirow{2}{*}{$\chi^{2}=4.11, d f=1, P=0.04$} \\
\hline & Male & 15(33.3\%) & $42(35.0 \%)$ & \\
\hline Work experience, y & Mean \pm SD & $12.5 \pm 4.9$ & $11.5 \pm 4.0$ & $t=0.77, P=0.65$ \\
\hline \multirow{2}{*}{ Educational level } & Graduate & $34(75.6 \%)$ & $98(81.7 \%)$ & \multirow{2}{*}{$\chi^{2}=5.22, d f=1, P=0.03$} \\
\hline & Postgraduate & $11(24.4 \%)$ & $22(18.3 \%)$ & \\
\hline \multirow[b]{2}{*}{ Workshop attendance } & Yes & 43(95.6\%) & $77(64.2 \%)$ & \multirow[b]{2}{*}{$\chi^{2}=3.95, d f=1, P=0.03$} \\
\hline & No & $2(44 \%)$ & $43(358 \%)$ & \\
\hline
\end{tabular}

Ilranian Rehabilitation Journal

Table 2. The teachers' general awareness and attitude about learning disabilities

\begin{tabular}{ccc}
\hline Groups & Total Scores of Teacher's Awareness (Mean \pm SD) & P \\
\hline Case $(n=45)$ & $29.5 \pm 2.5$ & $<0.001$ \\
Control $(n=120)$ & $20.5 \pm 5.5$ & \\
\hline
\end{tabular}


Table 3. Correlation coefficients of teachers' awareness and attitude scores with other independent variables

\begin{tabular}{cccccc}
\hline Teachers' Scores & Age & Gender & Work Experience & Educational Level & $\begin{array}{c}\text { Workshop } \\
\text { Attendance }\end{array}$ \\
\hline $\begin{array}{c}\text { Awareness test score } \\
\text { of teacher's viewpoint } \\
\text { (case group) }\end{array}$ & $r=0.06, \mathrm{P}=0.54$ & $\mathrm{r}=0.05, \mathrm{P}=0.60$ & $\mathrm{r}=0.53, \mathrm{P}<0.001$ & $\mathrm{r}=0.11, \mathrm{P}=0.42$ & $\mathrm{r}=0.29, \mathrm{P}<0.001$ \\
$\begin{array}{c}\text { Awareness test score } \\
\text { of teacher's viewpoint } \\
\text { (control group) }\end{array}$ & $\mathrm{r}=0.05, \mathrm{P}=0.66$ & $\mathrm{r}=0.04, \mathrm{P}=0.55$ & $\mathrm{r}=0.61, \mathrm{P}<0.001$ & $\mathrm{r}=0.40, \mathrm{P}=0.04$ & $\mathrm{r}=0.35, \mathrm{P}<0.001$ \\
\hline
\end{tabular}

IIranian Rehabilitation Journal

Table 4. Logistic regression analysis and predictors of student referral to speech therapy by teachers

\begin{tabular}{ccccc}
\hline \multirow{2}{*}{\begin{tabular}{c} 
Predictor Factors \\
\cline { 2 - 4 }
\end{tabular}} & \multicolumn{2}{c}{ Referring or Not Referring Students to Speech Therapy by Teachers } \\
\cline { 2 - 5 } Age & B & SE & df & P \\
\hline Gender & 0.189 & 0.121 & 1 & 0.20 \\
\hline Work experience & 0.100 & 0.324 & 1 & 0.22 \\
\hline Educational level & 0.480 & 0.101 & 1 & 0.041 \\
\hline Workshop attendance & 0.299 & 0.106 & 1 & 0.003 \\
\hline Awareness test score of teacher's viewpoint & 0.348 & 0.119 & 1 & $<0.001$ \\
\hline
\end{tabular}

IIranian Rehabilitation Journal

and Abdi et al. who found that primary school teachers had a low level of awareness about learning disabilities $[12,14]$. However, these data were inconsistent with Jamal and Al-Khatib study findings. In this study, teachers had a moderate knowledge about learning disabilities The reason of this result is the interaction of teachers with those who had activities in the field of learning disabilities, participating in training courses and, getting information from workshops, TV programs, radios, and learning disability journals [15].

The low level of teachers' awareness can be attributed to the incapability of teachers to identify invisible disabilities. Studies have reported that in the curriculum intended for Indian teachers, there are no specific curriculum or a workshop on signs and symptoms of children with learning disabilities. This can lead to a lack of awareness among teachers and consequently, lack of timely referral of students with special needs [13]. The case group teachers had a history of referring a student suspected of learning disabilities to speech therapies.

To determine the reason of significant difference between the two groups, the subjects' backgrounds were investigated. Comparisons revealed that factors such as teacher's gender, educational level, and history of participation in workshops were different between the two groups (Table 1). In addition, the correlation analysis suggested a direct and significant correlation between the level of awareness and attitude of teachers with their work experience, educational level and workshops attendance. In addition, there was no significant correlation between the level of awareness and attitude of teachers, and age and gender (Table 3 ).

This finding is in line with Abdi et al. and Arjamndi studies [2, 13]. However, it was inconsistent with Bhavya and Kamala study $[16,17]$. They also reported teachers with higher educational level had higher knowledge about learning disabilities. Arjmandi and Kakabarei also reported similar findings. They stated that education and gender had significant effects on teachers' knowledge about learning disabilities [2].

Kamala reported that gender had no effect on teachers' knowledge. He also demonstrated no significant differences between teachers with 1-5 years of teaching experience and those with more than 5 years of teaching experience in terms of knowledge about learning disabilities [17]. Bhavya also reported that educational level 
and gender had no effects on teachers' knowledge about learning disabilities [16]. Lingeswaran also reported that teaching experience had no effects on teachers' knowledge about learning disabilities [7].

The regression analysis suggested that teachers' teaching experience, their level of education, history of participation in workshops, and their awareness of learning disabilities can directly affect the referral of students to speech therapy centers by teachers. Obviously, teachers' participation in workshops can familiarize them with the diagnoses, causes and the specialists for resolving learning disabilities [11]. Moreover, teachers with higher educational level learn more about the educational issues and learning conditions among student, in addition to their specialized courses [8]. Teaching experience is another important factor illustrating the impact of managing students' issues. Certainly, one should not simply ignore the unique experiences of each teacher in dealing with students. The literature has also emphasized on the importance and impact of this issue on teachers' awareness of the different conditions of students $[13,16]$.

To explaining the reason for this finding, it can be said that recognizing the field of learning disabilities in the education system of Iran is relatively new. In addition, it can be indicative of the neglect of educational planners to update teachers' knowledge and motivation for selflearning [13]. Finally, the obtained results revealed that the higher the level of awareness and attitude of teachers about student learning disabilities, the more the students will be referred to appropriate centers. Therefore, it is important to increase the awareness of teachers by holding workshops, improving the educational level of teachers, and increasing their job experience besides increasing their awareness and attitudes about students' learning disabilities. The aforementioned actions may lead to the timely referrals of such children to specialized centers to overcome their disabilities.

\section{Conclusion}

Teachers directly address the educational and behavioural issues of students. Thus, they play a key role in diagnosing, referring, and solving students' problems. Creating a proper vision of these students is essential to have a suitable function for them. Treatment of these students will be a result of interaction between the family, teacher and therapist. Therefore, it is desirable for primary school teachers, as the most important levels of education, to have a thorough awareness of recognition of learning disabilities. This can be achieved through modification of teacher training programs and informing them via media on the needs of such children. In order to achieve this goal, workshops at regular intervals could be held. In addition, careful planning and the comprehensive support of the relevant authorities are required. Further research is required to more accurately assess teachers' awareness. The lack of teacher awareness measurement subtests was a limitation to this study.

\section{Ethical Considerations}

\section{Compliance with ethical guidelines}

The present study was approved by the Ethics Committee of University of Ahvaz Jundishapur Medical Sciences (Code: IR.AJUMS.REC.1396.559).

\section{Funding}

The current article was part of a Bachelor dissertation of Ebtesam Hozeily and was financially supported by Musculoskeletal Rehabilitation Research Center, Ahvaz Jundishapur University of Medical Sciences.

\section{Authors contributions}

The authors contributions is as follows: Conceptualization: Peyman Zamani, Neda Tahmasebi and Negin Moradi; Formal analysis, investigated, writing review \& editing: Peyman Zamani and Neda Tahmasebi; Writing-orginal draft preparation: Akram Ahmadi and Ebtesam Hozeily.

\section{Conflict of interest}

The authors declared no conflict of interest.

\section{Acknowledgements}

Authors are grateful to teachers who patiently participated in the present study.

\section{References}

[1] Kavale KA, Forness SR. What definitions of learning disability say and don't say: A critical analysis. Journal of Learning Disabilities. 2000; 33(3):239-56. [DOI:10.1177/00222194000330 0303] [PMID]

[2] Kakabaraee K, Arjmandnia AA, Afrooz GA. The study of awareness and capability of primary school teachers in identifying students with learning disability in the province of Kermanshah. Procedia-Social and Behavioral Sciences. 2012; 46:2615-9. [DOI:10.1016/j.sbspro.2012.05.534] 
[3] Shukla P, Agrawal G. Awareness of learning disabilities among teachers of primary schools. Online Journal of Multidisciplinary Research. 2015; 1(1):33-8.

[4] Wekesa WR, Poipoi MW, Wanyama R, Nyakwara BS. Early identification of learning disabilities among standard three pupils of public primary schools in Butere district, Kenya. Journal of Emerging Trends in Educational Research and Policy Studies. 2012; 3(4):695-700.

[5] Eslami M, Haghdoost AA, Afsaneh N, Hamideh RS. Prevalence of learning disability in primary school students in Kerman City. European Online Journal of Natural and Social Sciences. 2014; 3(3):534-540.

[6] Altarac M, Saroha E. Lifetime prevalence of learning disability among US children. Pediatrics. 2007; 119(Suppl. 1):S77S83. [DOI:10.1542/peds.2006-2089L] [PMID]

[7] Lingeswaran A. Assessing knowledge of primary school teachers on specific learning disabilities in two schools in India. Journal of Education and Health Promotion. 2013; 2:30. [DOI:10.4103/2277-9531.115807] [PMID] [PMCID]

[8] Kirk SA, Bateman B. Diagnosis and remediation of learning disabilities. Exceptional Children. 1962; 29(2):73-8. [DOI:10.11 77/001440296202900204]

[9] The American Psychiatric Association. Diagnostic and statistical manual of mental disorders. Philadelphia: The American Psychiatric Association; 2013. [DOI:10.1176/appi. books.9780890425596]

[10] Catts HW. The relationship between speech-language impairments and reading disabilities. Journal of Speech Language, and Hearing Research. 1993; 36(5):948-58. [DOI:10.1044/jshr.3605.948]

[11] Specht J. Educating exceptional children: Current issue for educators. Education Canada. 2004; 44(1):4-7.

[12] Kataoka M, Van Kraayenoord CE, Elkins J. Principals' and teachers' perceptions of learning disabilities: A study from Nara prefecture, Japan. Learning Disability Quarterly. 2004; 27(3):161-75. [DOI:10.2307/1593666]

[13] Abdi B, Moosavi SKS, Ghadiri Nejadian F, Jahromi M, Panahi Aboozar S. [Teachers' knowledge on learning disabilities in primary schools (Persian)]. Journal of Exceptional Children. 2010; 9(4):345-56.

[14] Moothedath S, Vranda MN. Knowledge of primary school teachers in identifying children with learning disabilities. Disability, CBR \& Inclusive Development. 2015; 26(3):68-76. [DOI:10.5463/dcid.v26i3.443]

[15] Al Khatib JM. A survey of general education teachers' knowledge of learning disabilities in Jordan. International Journal of Special Education. 2007; 22(1):72-6.

[16] Bhavya S, Chinnu CM, Christy EJ,Dayona T, Viji Prasad $\mathrm{C}$. The knowledge and attitude of teachers regarding specific learning disabilities among children: A descriptive approach. International Journal of Recent Scientific Research. 2015; 6(1):2636-41.

[17] Kamala R, Ramganesh E. Knowledge of specific learning disabilities among teacher educators in puducherry, Union territory in India. International Review of Social Sciences and Humanities. 2013; 6(1):168-75. 
This Page Intentionally Left Blank 